\title{
Torsional ultrasound mode versus combined torsional and conventional ultrasound mode phacoemulsification for eyes with hard cataract
}

This article was published in the following Dove Press journal:

Clinical Ophthalmology

I4 July 201 I

Number of times this article has been viewed

\author{
Mohamed A Fakhry ${ }^{1,2}$ \\ Malak I El Shazly' \\ 'Department of Ophthalmology, \\ Kasr El Aini Hospital, Cairo University, \\ Cairo, Egypt; ${ }^{2}$ Cataract and Refractive \\ Consultant, International Eye Hospital, \\ Cairo, Egypt
}

Purpose: To compare torsional versus combined torsional and conventional ultrasound modes in hard cataract surgery regarding ultrasound energy and time and effect on corneal endothelium.

Settings: Kasr El Aini hospital, Cairo University, and International Eye Hospital, Cairo, Egypt.

Methodology: Ninety-eight eyes of 63 patients were enrolled in this prospective comparative randomized masked clinical study. All eyes had nuclear cataracts of grades III and IV using the Lens Opacities Classification System III (LOCS III). Two groups were included, each having an equal number of eyes (49). The treatment for group A was combined torsional and conventional US mode phacoemulsification, and for group B torsional US mode phacoemulsification only. Pre- and post-operative assessments included best corrected visual acuity (BCVA), intraocular pressure (IOP), slit-lamp evaluation, and fundoscopic evaluation. Endothelial cell density (ECD) and central corneal thickness (CCT) were measured preoperatively, 1 day, 7 days, and 1 month postoperatively. All eyes were operated on using the Alcon Infiniti System (Alcon, Fort Worth, TX) with the quick chop technique. All eyes were implanted with AcrySof SA60AT (Alcon) intraocular lens (IOL). The main phaco outcome parameters included the mean ultrasound time (UST), the mean cumulative dissipated energy (CDE), and the percent of average torsional amplitude in position 3 (\%TUSiP3).

Results: Improvement in BCVA was statistically significant in both groups $(P<0.001)$. Comparing UST and CDE for both groups revealed results favoring the pure torsional group ( $P=0.002$ and $P<0.001$ for UST; $P=0.058$ and $P=0.009$ for CDE). As for \%TUSiP3, readings were higher for the pure torsional group $(P=0.03$ and $P=0.01)$. All changes of CCT, and ECD over time were found statistically significant using one-way ANOVA testing $(P<0.001)$.

Conclusion: Both modes are safe in hard cataract surgery, however the pure torsional mode showed less US energy used.

Keywords: torsional, cumulative dissipated energy, cataract

\section{Introduction}

Phacoemulsification has become the main choice of most ophthalmologists for elective cataract surgery. However, ultrasound (US) energy during phacoemulsification can carry the risk of endothelial cell loss and tissue damage, especially in hard cataracts. $^{1}$

In the conventional US mode, the phaco tip moves forward and backward (longitudinal), causing a jackhammer effect, which plays an important role, while the cavitation effect plays a minimal role. ${ }^{1}$ The longitudinal mode can produce a repulsion effect, because the phaco tip pushes the nucleus away when it moves forward.
Correspondence: Mohamed A Fakhry I4 Abou Hazem Street, Madkour, Haram, Giza, Egypt

Tel +20 25862810

Mob +20106 678788

Email fakhryerf@hotmail.com 
The OZil Torsional system (Infiniti, Alcon, Fort Worth, TX) is a hardware and software upgrade, which includes a dedicated handpiece that produces side-to-side rotary oscillations of the phaco tip.

Compared with the jackhammer motion in conventional phaco, the OZil Torsional oscillation sheers the lens material with virtually no repulsion, thereby dramatically improving the flow of nuclear material into the phacoemulsification tip, ${ }^{2}$ and reducing US energy required for lens removal without compromising efficiency. ${ }^{3}$

However, the torsional system works at a lower frequency: $32 \mathrm{kHz}$ rather than the $40-45 \mathrm{kHz}$ in conventional phaco, and theoretically reduces efficiency in lens removal, especially with a hard nucleus.

In this study, we sought to compare the safety, efficiency, and postoperative clinical outcome using combined torsional and conventional US mode, versus torsional US mode in hard cataracts.

\section{Patients and methods}

Ninety-eight eyes of 63 patients ( 33 males, 30 females), having elective phacoemulsification and IOL implantation, were enrolled in this prospective comparative randomized masked clinical study which was conducted from December 2009 to January 2011. The average age was $61.3 \pm 5$ years (range 55 to 72 ): 35 patients had bilateral phacoemulsification.

The grading of cataract was determined according to the Lens Opacities Classification System III (LOCS III). Eyes with nuclear opalescence (NO) grades III and IV were included in the study.

All eyes had a corneal endothelial cell count greater than $1500 / \mathrm{mm}^{2}$. Eyes with previous trauma, inflammation, intra-ocular surgery or pathology, or lens subluxation, were excluded. All patients signed an informed consent for the procedure.

The eligible eyes were randomly allocated (according to a randomization code revealed at time of surgery) into one of the two groups having equal number of eyes (49). Group A received combined torsional and conventional US mode phacoemulsification. Group B received torsional US mode phacoemulsification only.

All the pre- and post-operative assessments were performed by one ophthalmologist (MS) who was masked to the procedure assigned (the surgical note was made inaccessible to the evaluating ophthalmologist). Pre- and post-operative assessments included corrected distance visual acuity (CDVA) using logMAR standards, intraocular pressure (IOP) measurement by Goldmann's applanation tonometry, slit-lamp evaluation, and fundoscopic evaluation.
Endothelial cell density (ECD) was measured preoperatively, 1 day, 1 week, and 1 month postoperatively, using the noncontact specular microscope (Tomey EM-3000; Tomey, Tennenlohe, Germany).

The central corneal thickness (CCT) was measured preoperatively, then 1 day, 1 week, and 1 month postoperatively using Fourier-domain anterior optical coherence tomography (OCT), a 3D OCT-1000 (v 3.01, Mark II; Topcon Corporation, Tokyo, Japan).

The Alcon Infiniti System (Alcon, Fort Worth, TX) was used in all cases, and all surgeries were performed by the same surgeon (MF). For all groups, a MicroTip $0.9 \mathrm{~mm}$ ABS phaco tip (45, flared Kelman) was used. The settings are shown in Table 1.

All patients were treated under local anesthesia: peribulbar; Lidocaine HCL 2\% (Debocaine, Sigma pharmaceutical Co, Al-Debeiky Pharma Co, A.R.E.). A 2.4-mm self-sealing limbal incision was made. A VISCOAT ${ }^{\circledR}$ (Alcon Inc, Fort Worth, TX) ophthalmic viscosurgical device (OVD) (sodium chondroitin sulfate $4.0 \%$-sodium hyaluronate $3.0 \%$ ) was used to reform and stabilize the surgical planes and protect the corneal endothelium. A 5.5- to 6.0-mm continuous curvilinear capsulorhexis was performed with a 26-gauge needle. The quick chop technique was used for all eyes. All eyes were implanted with an AcrySof SA60AT (Alcon) intraocular lens (IOL), injected through the 2.4-mm incision, followed by aspiration of VISCOAT and hydration of the incision.

The main phaco parameters were calculated and displayed on a machine monitor and included:

1. Mean ultrasound time (UST), which represents how many seconds the foot pedal remained in the third position.

2. Mean cumulative dissipated energy (CDE) which indicates the mean percentage of power spent during the UST. The CDE was calculated as follows: $\mathrm{CDE}=$ mean US power $\times$ UST. In torsional mode, the CDE was calculated

Table I Parameters for torsional and mixed torsional and longitudinal ultrasound modes

\begin{tabular}{lll}
\hline Group & $\begin{array}{l}\text { Mixed (linear } \\
\text { torsional }+ \\
\text { longitudinal) US }\end{array}$ & $\begin{array}{l}\text { Fixed } \\
\text { torsional US }\end{array}$ \\
\hline $\begin{array}{l}\text { Torsional amplitude } \\
\text { (continuous) }\end{array}$ & $100 \%$ (linear) & $100 \%$ (fixed) \\
$\begin{array}{l}\text { Longitudinal US power (\%) } \\
\text { (burst; width } 40 \text { ms; } \\
\text { off time } 30 \text { milliseconds) }\end{array}$ & $30 \%$ (linear) & - \\
$\begin{array}{l}\text { Vacuum limit (mmHg) } \\
\text { (fixed) }\end{array}$ & 400 (fixed) & 400 (fixed) \\
$\begin{array}{l}\text { Aspiration flow rate } \\
\left(\mathrm{cm}^{3} / \text { minute) (fixed) }\right.\end{array}$ & 40 (fixed) & 40 (fixed) \\
\hline
\end{tabular}

Abbreviation: US, ultrasound. 
Table 2 Age, sex, bilaterality, and nuclear density for both groups

\begin{tabular}{|c|c|c|}
\hline & $\begin{array}{l}\text { Mixed torsional } \\
\text { and longitudinal }\end{array}$ & Pure torsional \\
\hline Age & $58.3 \pm 4$ years & $62 \pm 3$ years \\
\hline Sex & 17 males, 14 females & 16 males, 16 females \\
\hline Bilaterality & 19 & 16 \\
\hline \multicolumn{3}{|c|}{ Nuclear density } \\
\hline NO grade III & 29 & 27 \\
\hline NO grade IV & 20 & 22 \\
\hline
\end{tabular}

Note: Nucleus density grade was scored according to LOCS III. Abbreviation: NO, nuclear opalescence.

as follows: torsional amplitude $\times$ torsional time $\times 0.4$. The frequency of the phaco tip in torsional mode was $80 \%$ of that in standard phaco $(32 \mathrm{kHz}$ in torsional vs $40 \mathrm{kHz}$ in standard phaco), and the stroke distance of the phaco tip in torsional mode was half that in standard phaco. This helped justify the coefficient of 0.4 .

3. The percent of average torsional amplitude in position 3 (\%TUSiP3). This parameter evaluates torsional US energy in position 3. Other evaluation parameters included CCT and ECD changes.

Patients were examined 1 day, 1 week, and 1 month after surgery.

The postoperative regimen included a mixed corticosteroid and antibiotic eye drop (Ofloxacin 0.3\%, and Dexamethasone $0.1 \%$; Dexaflox ${ }^{\mathrm{TM}}$, Jamjoom Pharmaceuticals, Jeddah, Saudi Arabia) six times a day, gradually tapered over 1 month, and a mixed corticosteroid and antibiotic eye ointment (Tobramycine $0.3 \% \mathrm{mg}$ and Dexamethasone $0.05 \%$; Tobradex $^{\mathrm{TM}}$, Alcon) for 1 week.

Corneal edema was recorded yet not considered as a main outcome in this study.

The data was coded and entered using the statistical package SPSS (v 15; SPSS, Inc, IBM, Chicago, IL). The data was summarized using descriptive statistics: mean, standard

Table 3 CDVA pre- and I month postoperatively

\begin{tabular}{lcl}
\hline & $\begin{array}{l}\text { Mixed torsional } \\
\text { and longitudinal }\end{array}$ & Pure torsional \\
\hline Pre CDVA & & $0.8 \pm 0.2$ \\
NO grade III & $0.83 \pm 0.3$ & $1.2 \pm 0.4$ \\
NO grade IV & $I .1 \pm 0.2$ & \\
Post CDVA & & \\
(I month postop) & & \\
NO grade III & $0.12 \pm 0.1(P<0.00 I)$ & $0.1 I \pm 0.2(P<0.00 \mathrm{I})$ \\
NO grade IV & $0.13 \pm 0.3(P<0.00 \mathrm{I})$ & $0.13 \pm 0.4(P<0.00 \mathrm{I})$ \\
\hline
\end{tabular}

Abbreviations: CDVA, Corrected Distant Visual Acuity expressed in standards of LogMAR; NO, nuclear opalescence; postop, postoperative.
Table 4 Phaco parameters (UST, CDE, \%TUSiP3) for both groups

\begin{tabular}{|c|c|c|}
\hline & $\begin{array}{l}\text { Mixed torsional } \\
\text { and longitudinal }\end{array}$ & Pure torsional \\
\hline \multicolumn{3}{|c|}{ UST (seconds) } \\
\hline NO grade III & $48.4 \pm 14$ & $47.1 \pm 18(P=0.002)$ \\
\hline NO grade IV & $69.6 \pm 20$ & $67.7 \pm 17(P<0.001)$ \\
\hline \multicolumn{3}{|l|}{ CDE } \\
\hline NO grade III & $15.3 \pm 8$ & $15.2 \pm 10(P=0.058)$ \\
\hline NO grade IV & $23.5 \pm 11$ & $22.9 \pm 12(P=0.009)$ \\
\hline \multicolumn{3}{|l|}{ \%TUSiP3 } \\
\hline NO grade III & $32.3 \pm 12$ & $32.6 \pm 14(P=0.03)$ \\
\hline NO grade IV & $38.5 \pm 20$ & $39.1 \pm 12(P=0.01)$ \\
\hline
\end{tabular}

Abbreviations: UST, ultrasound time; CDE, cumulative dissipative energy; \%TUSiP3, percentage of torsional ultrasound power in position 3; NO, nuclear opalescence.

deviation, and $95 \%$ confidence interval of difference. Statistical differences were tested using paired sample, independent sample $t$-test, and one-way ANOVA tests. $P$-values less than or equal to 0.05 were considered statistically significant.

\section{Results}

Descriptive data in each group regarding age, sex, bilaterality, and nuclear density are shown in Table 2. As for BCVA, Table 3 shows data for both pre- and 1 month postoperative BCVA. Comparing pre- and 1 month postoperative BCVA (using paired sample $t$-test) showed highly statistically significant improvement in BCVA for both NO grades in both groups $(P<0.001)$. However, comparing the two groups for 1 month postoperative BCVA (using independent sample $t$-test) showed no statistical significance $(P=0.11$ for $\mathrm{NO}$ grade III, and $P=0.34$ for NO grade IV).

Descriptive data regarding phaco parameters: UST, CDE, and \%TUSiP3 are illustrated in Table 4. Statistical analysis was done using the independent sample $t$-test. Comparing UST for both groups revealed statistically significant results favoring the pure torsional group $(P=0.002$ for NO grade III, and $P<0.001$ for NO grade IV). Figure 1 shows a bar graph describing UST for both groups. Comparing CDE also revealed results favoring pure torsional group $(P=0.3$, statistically insignificant, for NO grade III, and $P=0.001$ for NO grade IV). Figure 2 shows a bar graph describing CDE for both groups. As for \%TUSiP3, readings were higher for the pure torsional group $(P=0.2$ for NO grade III, $P=0.01$ for NO grade IV).

Data regarding changes in CCT, and ECD over time are shown in Table 5. Figures 3 and 4 show preoperative and 1-month postoperative CCT as measured by anterior OCT. All changes of CCT, and ECD over time were found statistically significant using one-way ANOVA testing $(P<0.001)$. 


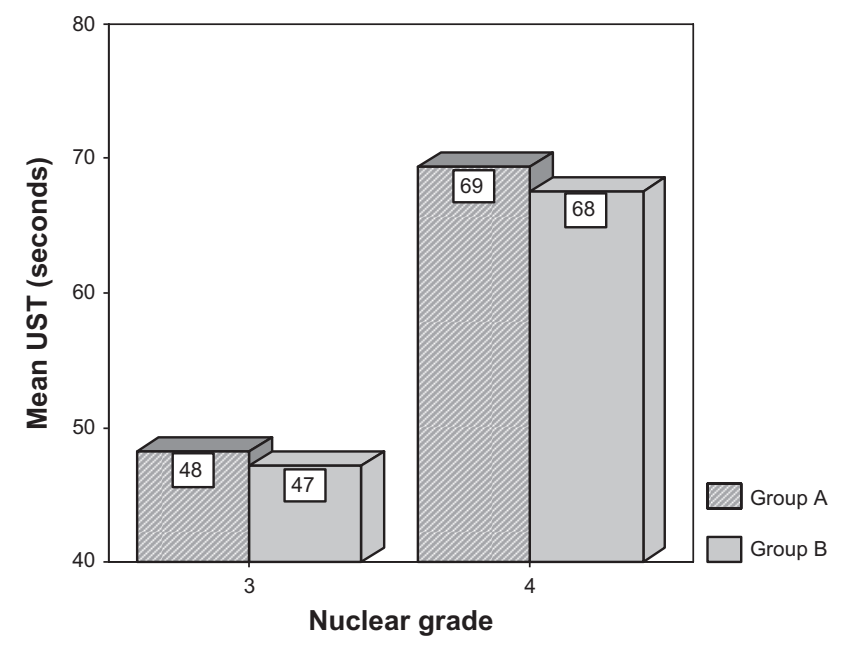

Figure I Bar graph describing UST for both groups. Abbreviation: UST, ultrasound time.

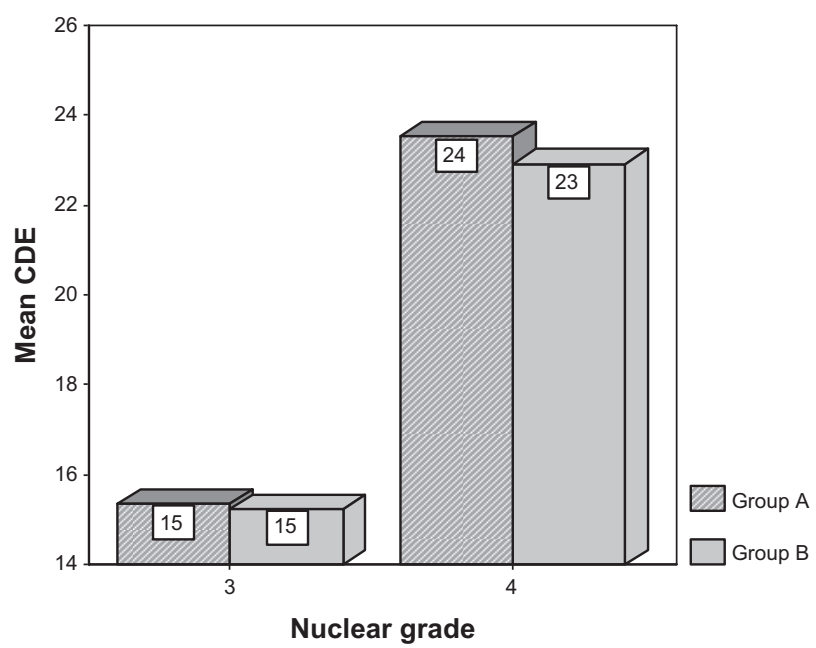

Figure 2 Bar graph describing CDE for both groups. Abbreviation: $C D E$, cumulative dissipated energy.

\section{Comparing groups}

(A) CCT change at first day postoperative between the two groups was statistically significant in favor of the torsional group ( $P=0.01,95 \%$ confidence interval [CI]: $0.5-2.6$ for NO grade III, and $P<0.001,95 \%$ CI: $4.1-5.2$ for NO grade IV), and at 1 week ( $P=0.002,95 \%$ CI: $0.4-1.7$ for NO grade III, and $P=0.001,95 \%$ CI: $0.5-1.4$ for NO grade IV), however it was insignificant at 1 month $(P=0.68,95 \%$ CI: $0.3-1.1$ for NO grade III, and $P=0.059,95 \%$ CI: $0.4-1.0$ for NO grade IV). (B) ECD change was statistically significant in favor of the torsional group in all follow-ups for both grades $(P<0.001)$.

No specific results were found regarding IOP and fundus findings as they were within normal range for all eyes. Corneal edema was not used as an evaluating parameter in this study, as CCT and ECD were proved to be more reliable regarding corneal endothelial surgical trauma.

\section{Discussion}

The use of combined torsional and conventional US mode in the management of cataract grade III and IV is performed by many surgeons. Many authors have suggested a better efficiency with the torsional mode rather than the conventional mode, but not the combined torsional and conventional US mode. ${ }^{3}$ Liu et al stated that the mean UST and CDE were significantly lower in the torsional group than in the conventional US group for each nucleus density grade. ${ }^{3}$

A previous study done by Bozkurt et $\mathrm{al}^{4}$ which included 2 groups, conventional versus torsional US, found that the average UST and CDE were not statistically different between the conventional and the torsional phaco groups, but the average total equivalent ultrasound power in position 3 (\%USTEPiP3)

Table 5 CCT and ECD over time for both groups

\begin{tabular}{|c|c|c|c|c|c|}
\hline & & $\begin{array}{l}\text { Preop } \\
\text { Mean }+ \text { SD }\end{array}$ & $\begin{array}{l}\text { I day } \\
\text { Mean } \pm \text { SD (change) }\end{array}$ & $\begin{array}{l}7 \text { days } \\
\text { Mean } \pm \text { SD (change) }\end{array}$ & $\begin{array}{l}30 \text { days } \\
\text { Mean } \pm \text { SD (change) }\end{array}$ \\
\hline \multirow[t]{6}{*}{ Mixed } & CCT & & & & \\
\hline & NO grade III & $515.3 \pm 22$ & $584 \pm 43(69)$ & $552 \pm 38(37)$ & $530 \pm 52(15)(P<0.001)$ \\
\hline & NO grade IV & $505.8 \pm 13$ & $602 \pm 32(97)$ & $572 \pm 29(67)$ & $536 \pm 36(31)(P<0.001)$ \\
\hline & ECD & & & & \\
\hline & NO grade III & $2716 \pm 95$ & $2580 \pm 121(136)$ & $2545 \pm 102(|7|)$ & $2532 \pm 108(184)(P<0.001)$ \\
\hline & NO grade IV & $2695 \pm|4|$ & $2502 \pm 133(193)$ & $2463 \pm 98(232)$ & $2450 \pm 141(245)(P<0.001)$ \\
\hline \multirow[t]{6}{*}{ Pure } & CCT & & & & \\
\hline & NO grade III & $502.3 \pm 41$ & $569 \pm 61(67)$ & $538 \pm 57(36)$ & $517 \pm 38(15)(P<0.001)$ \\
\hline & NO grade IV & $518.8 \pm 52$ & $610 \pm 76(92)$ & $584 \pm 81(66)$ & $548 \pm 75(30)(P<0.001)$ \\
\hline & ECD & & & & \\
\hline & NO grade III & $2630 \pm 105$ & $2500 \pm 144(130)$ & $2472 \pm 175(158)$ & $2465 \pm 116(165)(P<0.00 I)$ \\
\hline & NO grade IV & $2814 \pm 122$ & $2634 \pm 138(180)$ & $26 I I \pm 109(203)$ & $2601 \pm 138(213)(P<0.001)$ \\
\hline
\end{tabular}

Abbreviations: $\mathrm{CCT}$, central corneal thickness; $\mathrm{ECD}$, endothelial cell density; NO, nuclear opalescence; preop, preoperative. 


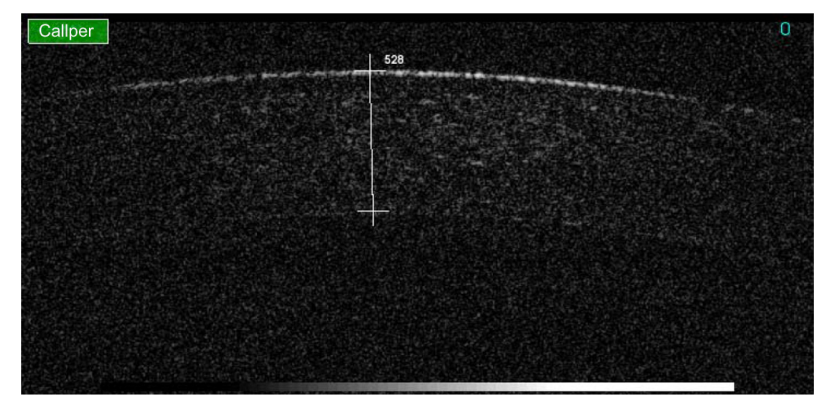

Figure 3 CCT preoperatively $(528 \mu \mathrm{m})$.

Abbreviation: CCT, central corneal thickness.

in the OZil group was found to be significantly lower than that in the conventional phaco group. This differs from the parameter we used (\%TUSiP3) which isolates and measures torsional power in position 3 in both groups. It was higher for the pure torsional group which had a fixed mode rather than the combined group which had a linear torsional mode.

Also, in a study done by Reuschel et al, ${ }^{5}$ there were statistically significant differences in mean US time, CDE, and \%USTEPiP3 between the torsional group and the longitudinal group.

It has been demonstrated that the CDE and endothelial cell loss in torsional mode were lower than those in conventional mode in cataracts of all grades. ${ }^{3}$

Also, a higher efficiency and safety of fixed torsional US mode was observed in hard nucleus cataracts. ${ }^{6}$

The above-mentioned facts gave us the idea of studying the effect of combined torsional and conventional versus torsional US mode in hard cataracts.

Our study showed lower UST values in the torsional mode for both grades $(P=0.002$ for grade III, and $P<0.001$ for grade IV). CDE was only significantly in favor of the torsional group for grade IV $(P=0.001)$. This can be explained by the fact that the torsional mode provides less lens fragment repulsion at the tip and accordingly less UST and less CDE

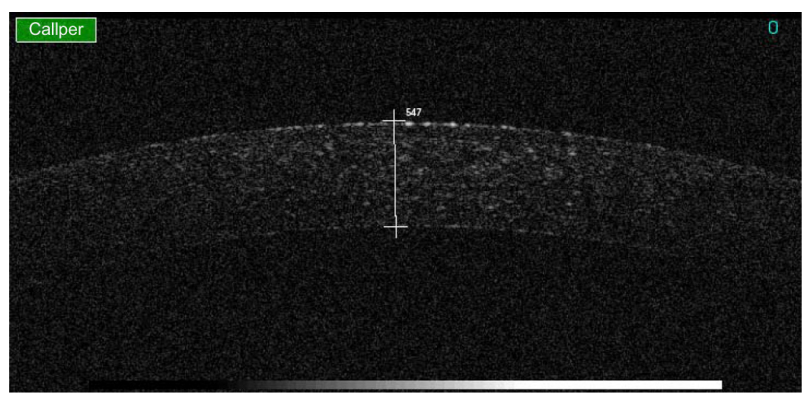

Figure 4 CCT of same eye I month postoperatively $(547 \mu \mathrm{m})$. Abbreviation: CCT, central corneal thickness. which, in our opinion, makes it more safe and effective than the combined torsional and conventional mode. Percentage TUSiP3 values were higher for the torsional mode (significant for grade IV, $P=0.01$ ) because the torsional US was set to fixed continuous mode. This choice made the torsional US effective in hard cataracts, but with the combined torsional and conventional US mode we chose to use linear burst conventional US mode in an attempt to decrease overall CDE and UST.

The changes in ECD and CCT reflect the safety of the procedure as they are indicators for surgical induced corneal trauma..$^{8,9}$

In our study, comparison for increase in CCT was significantly in favor of the torsional group during the early postoperative period, with no difference observed at 1 month, similar to the results of Kim et al, ${ }^{7}$ who also performed a comparative study between torsional and conventional mode phacoemulsification in moderate and hard cataracts.

The change in ECD was statistically significant in favor of the torsional group in all follow-ups for both grades $(P<0.001)$. Similar findings were reported by Zeng et al. ${ }^{6}$ These findings are consistent with other reports where endothelial cell loss was correlated with ultrasound energy applied. ${ }^{10,11}$

Corneal thickness returned nearly to baseline 1 month after surgery, while endothelial loss persisted, being compensated by the remaining endothelial cells.

The mean BCVA is quite similar between the two groups with no statistically significant difference.

We conclude that both US modes are effective in management of grades III and IV cataracts. However, the pure torsional group uses less US energy and time. Further studies involving the use of an intelligent phaco (IP) option with torsional mode are recommended, as it might have the same efficiency without the repulsion effect of longitudinal US when combined with the torsional US mode.

\section{Disclosure}

The authors report no conflicts of interest in this work.

\section{References}

1. Zacharias J. Role of cavitation in the phacoemulsification process $J$ Cataract Refract Surg. 2008;34(5):846-852.

2. Davison JA. Cumulative tip travel and implied followability of longitudinal and torsional phacoemulsification. $J$ Cataract Refract Surg. 2008;34(6):986-990.

3. Liu Y, Zeng M, Liu X, et al. Torsional mode versus conventional ultrasound mode phacoemulsification: randomized comparative clinical study. J Cataract Refract Surg. 2007;33(2):287-292. 
4. Bozkurt E, Bayraktar S, Yazgan S, et al. Comparison of conventional and torsional mode (OZil) phacoemulsification: randomized prospective clinical study. European J Ophthalmol. 2009;19(6):984-989.

5. Reuschel A, Bogatsch H, Barth T, Wiedemann R. Comparison of endothelial changes and power settings between torsional and longitudinal phacoemulsification. J Cataract Refract Surg. 2010;36(11): 1855-1861.

6. Zeng M, Liu X, Liu Y, et al. Torsional ultrasound modality for hard nucleus phacoemulsification cataract extraction. Br J Ophthalmol. 2008; 92(8):1092-1096.

7. Kim DH, Wee WR, Lee JH, Kim MK. The comparison between torsional and conventional mode phacoemulsification in moderate and hard cataracts. Korean J Ophthalmol. 2010;24(6):336-340.
8. Kim EK, Cristol SM, Geroski DH, McCarey BE, Edelhauser HF. Corneal endothelial damage by air bubbles during phacoemulsification. Arch Ophthalmol. 1997;115(1):81-88.

9. Milla E, Verges C, Cipres M. Corneal endothelium evaluation after phacoemulsification with continuous anterior chamber infusion. Cornea. 2005;24(3):278-282.

10. Ventura AC, Walti R, Bohnke M. Corneal thickness and endothelial density before and after cataract surgery. Br J Ophthalmol. 2001; 85(1):18-20.

11. Zetterstrom C, Laurell CG. Comparison of endothelial cell loss and phacoemulsification energy during endocapsular phacoemulsification surgery. J Cataract Refract Surg. 1995;21(1):55-58.
Clinical Ophthalmology

\section{Publish your work in this journal}

Clinical Ophthalmology is an international, peer-reviewed journal covering all subspecialties within ophthalmology. Key topics include: Optometry; Visual science; Pharmacology and drug therapy in eye diseases; Basic Sciences; Primary and Secondary eye care; Patient Safety and Quality of Care Improvements. This journal is indexed on

\footnotetext{
Submit your manuscript here: http://www.dovepress.com/clinical-ophthalmology-journal
}

\section{Dovepress}

PubMed Central and CAS, and is the official journal of The Society of Clinical Ophthalmology (SCO). The manuscript management system is completely online and includes a very quick and fair peer-review system, which is all easy to use. Visit http://www.dovepress.com/ testimonials.php to read real quotes from published authors. 